\title{
Carbon footprint of laptops for export from China: empirical results and policy implications
}

\author{
Jingru Liu*, Dong Yang, Bin Lu, Jieqiong Zhang \\ State Key Laboratory of Urban and Regional Ecology, Research Center for Eco-Environmental Sciences, Chinese Academy of Sciences, 18 Shuangqing Road,
} Beijing, 100085, PR China

\section{A R T I C L E I N F O}

\section{Article history:}

Received 14 September 2015

Received in revised form

10 November 2015

Accepted 11 November 2015

Available online 1 December 2015

\section{Keywords:}

Export product

Supply chain

Carbon footprint

Life cycle analysis

Trade policy

\begin{abstract}
A B S T R A C T
China's laptop exports account for more than $70 \%$ of global laptop shipments by volume. Laptop is a typical import-and-assembly processing trade product in the machinery and electrical equipmentmanufacturing sector and comprises nearly $60 \%$ of China's total export value. The laptop sector is also carbon emissions intensive and contributes heavily to China's carbon emissions problem. To study the laptop sector's impact on carbon emissions, we first developed a carbon footprint map for the product across its supply chain, which allowed us to identify the emission contributions of each component and the production process as a whole. Then, using Simapro software and life cycle inventory data derived from the bottom-up life cycle-analysis method, we calculated the carbon footprint of laptop production. The results show that $33.3 \%$ of the carbon emissions from the production of export laptops originate from components produced abroad, while $66.7 \%$ is derived mainly from components produced domestically. Finally, we discuss the uncertainties in our approach and the trade policy implications of our research results.
\end{abstract}

() 2015 Elsevier Ltd. All rights reserved.

\section{Background}

China is the largest carbon emitter in the world (Gregg et al., 2008), with goods and service exports yielding 20-40\% of China's domestic carbon emissions, depending on the data sources and research methods used (Shui et al., 2006; Pan et al., 2008; Wang et al., 2008; Weber et al., 2008; Atkinson et al., 2011; Feng et al., 2013). As a fundamentally export-driven sector and an important global supplier, the machinery and electrical equipment manufacturing (MEM) sector constitutes nearly $60 \%$ of China's total export value. It is also a carbon-sensitive sector that produces $0.25 \%$ more carbon emissions for every $1 \%$ increase in output (Liu and Lu, 2010). Within this sector, computer exports account for approximately $15-30 \%$ of the emissions resulting from China's exports (Xu et al., 2010, 2011. Cui et al., 2015). As the world's factory, China produced more than $90 \%$ of the world's personal computer products in 2012; laptops were the largest component of this sector, accounting for approximately $51.5 \%$ of total production.

\footnotetext{
* Corresponding author. State Key Laboratory of Urban and Regional Ecology, Research Center for Eco-Environmental Sciences, Chinese Academy of Sciences, 18 Shuangqing Road, Haidian, 100085, PR China.

E-mail address: liujingru@rcees.ac.cn (J. Liu).
}

Carbon footprint is a measure of the total amount of carbon dioxide emissions directly and indirectly caused by an activity or accumulated over the life cycle of a product (Wiedmann and Minx, 2008). The term "carbon footprint" has recently come into wide use among academics and practitioners as a way to discuss productionbased or consumption-based emission responsibilities (Peters et al., 2006, 2011; Weber et al., 2009; Davis and Caldeira, 2010). The calculation of a product's carbon footprint is based on the life cycle assessment (LCA) method, which can be implemented as a bottomup process-sum LCA or a top-down input-output LCA (IO-LCA). The most common methodology used to estimate the emissions associated with international trade is the top-down IO-LCA. The MIOT and GTWP databases have been widely used to calculate carbon emissions embedded in international trade at the national and supra-national levels (Peters et al., 2008; Xu et al., 2010; Skelton et al., 2011; Su et al., 2011; Lindner et al., 2012). However, this method has certain shortcomings, including its inability to account for the differences in technological level and industrial structure between importing and exporting countries.

Although the calculation of a process-sum LCA is time- and labour-intensive, it does provide a good framework for developing a detailed carbon process map of a product across its supply chain (Lee, 2011). Additionally, it helps clarify the geographical separation 


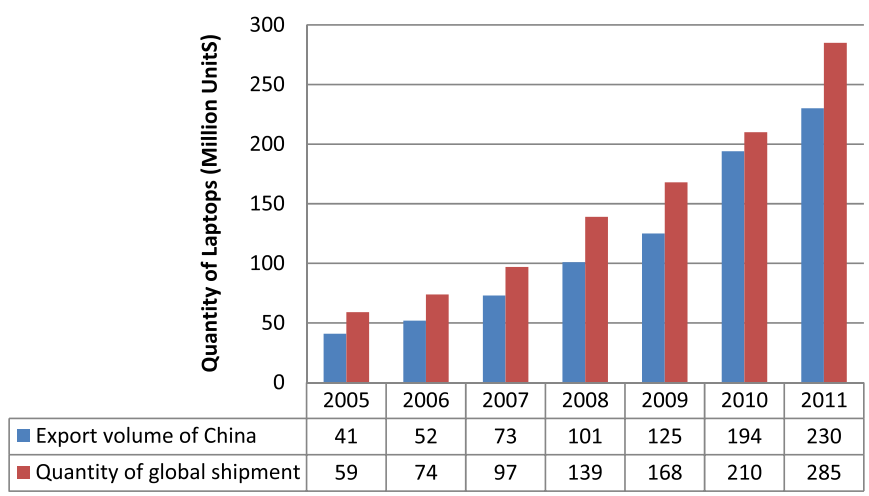

Fig. 1. China's laptop export volume and global laptop sales from 2005 to 2011.

of production and consumption activities, answering the fundamental question of who is responsible for what emissions (Caney, 2009).

The purposes of this study are to calculate the "cradle-tofreight" carbon footprint generated by China's export of laptops using the bottom-up process-sum LCA approach and to define the geographical distribution of laptop emissions (inside and outside China). We developed a product carbon footprint map across the laptop supply chain, which allowed us to identify the contributions of each component and process to laptop-related emissions (Kim et al., 2001). Identifying the greenhouse gas (GHG) emission patterns and key processes with the greatest carbon footprint contributions was emphasized to provide scientific support for decision makers developing low-carbon export policies. The carbon emissions generated by the production or processing of components and parts within China were calculated using our research centre's Life Cycle Inventory (LCI) databases. On-site data combined with information from a series of industrial reports were used to map out the laptop supply chain. The databases in Simapro 7.3 were used to calculate carbon emissions generated by the production of components outside of China.

\section{Overview of laptop exports from China}

In recent years, laptops have been the fastest growing export sector by volume in China. Fig. 1 illustrates the consistent increase in export volume from 2005 to 2011 (General Administration of Customs, 2013).

Comparisons between China's laptop export volume and the quantity of global laptop shipments (Fig. 1) reveal that more than $70 \%$ of global laptop sales originated from China between 2005 and 2011. A laptop is a typical import-and-assembly processing trade product. This refers to the business of importing materials, parts and components from abroad and the processing or assembly of those parts by enterprises within the exporting country, followed by the export of the finished products. More than $95 \%$ of China's export laptops are processing-trade products. The United States and the EU countries are the primary importers of these products, receiving approximately $60 \%$ of laptop exports from China.

By synthesizing recent industrial reports on laptop exports, field surveys and expert interviews, we were able to summarize the laptop export supply chain, as shown in Fig. 2. Almost all of the high-tech core electronic components or parts, such as hard drives, chipsets, and optical drivers, were produced abroad in countries such as the USA, Japan and Korea (Eugster et al., 2007; Liu, 2011). Non-core components and miscellaneous accessories were typically manufactured or assembled in China. The core components and intermediate materials produced outside China were transported to Chinese manufacturers for assembly into finished products. After final assembly, the finished products were then exported.

China has become a major importer of hard drives because of this process. The quantities of hard drives imported to China increased from 207.54 million set in 2008 to 319.96 unit set in 2011. In 2011, the number of imported hard drives exceeded the number of laptops exported by threefold. This difference suggests that almost all laptop hard drives used in the laptop-manufacturing process are imported.

\section{Methods and data}

\subsection{Goal, scope and system boundaries}

\subsubsection{Functional unit}

A 14-inch Hewlett-Packard (HP) laptop was chosen as the functional unit for this study. According to a survey by PC ONLINE (http://www.pconline.com.cn), the 14-inch HP laptop is the most popular laptop worldwide and is a typical high-volume, mainstream business laptop. Therefore, it can reliably represent a range of similar laptop products. A complete export laptop consists of a

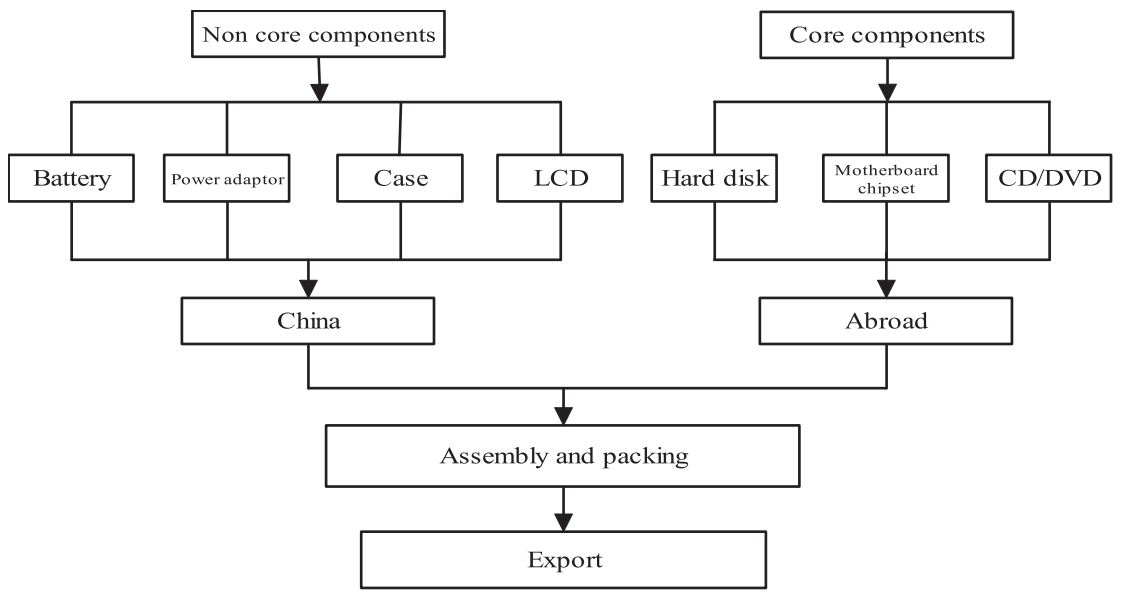

Fig. 2. Industry network diagram of laptop exports from China. 
Table 1

Main components of an HP 14-inch laptop.

\begin{tabular}{ll}
\hline Component & Weight \\
\hline Lithium battery & $0.216 \mathrm{~kg}$ \\
Hard drive & $0.16 \mathrm{~kg}$ \\
Liquid crystal display & $0.35 \mathrm{~kg}$ \\
CD-ROM driver & $1 \mathrm{P}$ \\
Power adapter & $1 \mathrm{P}$ \\
Casing & $0.544 \mathrm{~kg}$ \\
Motherboard & $1 \mathrm{P}$ \\
Plug & $0.15 \mathrm{~kg}$ \\
\hline
\end{tabular}

host, its hardware and its software configurations. The primary components of the selected product are listed in Table 1.

\subsubsection{System boundaries}

Because our research object is a typical export product, we defined our research product boundaries as "cradle-to-freight". In other words, we considered the steps from material extraction until final assembly, including the production of raw materials; component production, processing, assembly and packaging. The manufacturing phase was particularly difficult to analyse because of the large number of highly complex processes involved (Teehan and Kandikar, 2012). To make this assessment feasible, we first conducted a literature review. Relevant studies have shown that the carbon footprint of major components, such as motherboards, monitors, and batteries, accounts for more than $95 \%$ of the emissions produced during the laptop-production process (O'Connell and Stutz, 2010). Based on this knowledge and data availability, the carbon footprint of the sample HP laptop was derived from a study of the key parts and related GHG emissions depicted in Fig. 3.

According to the reviewed literature and the description of key parts outlined above, a simple scenario for the production of export laptops in China can be described as follows:

1) In China:

- Raw material extraction for processing into intermediate materials and components and subassembly of non-core components, including lithium batteries;

- Liquid crystal display (LCD) assembly;

- Lithium battery production;

- Laptop assembly;

- Laptop packaging;

- Assembly of non-core components, e.g., surface mounting, screen printing, component mounting, soldering processes, coating processes, and the application of ancillary materials, such as coatings, paints, adhesives, and greases;

- Material packaging for final transportation;

- Motherboard assembly.

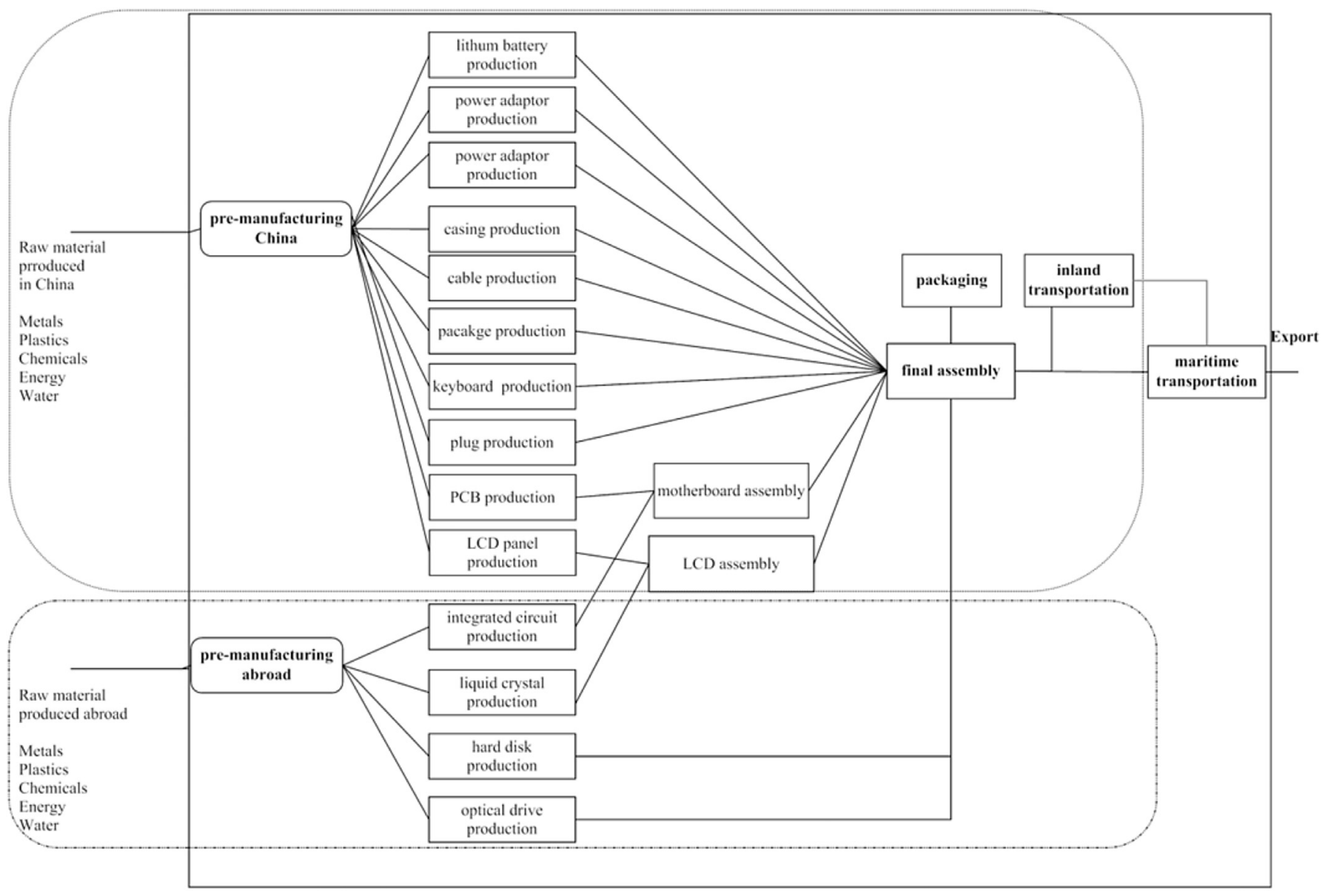

Boundary of domestic manufacturing

Fig. 3. System boundaries of export laptop production. 
2) Abroad:

- Production of motherboard ICs;

- Production of glass substrates and liquid crystals;

- Production of CD ROMs;

- Production of hard drives.

\subsection{Data sources}

Generic data obtained from the Simapro and RCEES LCI databases (Sun et al., 2014; Yang et al., 2015) were used in the upstream process analysis. Certain assumptions were made for each life cycle phase, as outlined below. The RCEES LCI database was developed based on Simapro software from the year 2000. More than 1000 units and processes are covered by this source, including transportation and waste-treatment processes, as well as the production of metals, minerals, plastics, water, chemicals, fuels, and energy. To generate data on these processes, the generic parameters of laptop computer-production processes in China were obtained from industrial reports and the relevant literature and integrated into the RCEES LCI database for the carbon footprint calculation. Electronic datasets available in the Simapro software suite were used to calculate the carbon footprint of the external production processes.

\subsection{Life cycle inventory}

Manufacturing contributes significantly to the carbon footprint of laptop production. According to a Dell research report (O'Connell and Stutz, 2010), production of the motherboard, the display, the chassis and the battery accounts for the majority of total GHG emissions generated in the laptop manufacturing process. The carbon footprint created by one of these components includes the total carbon emissions from the extraction of the raw materials required for its creation and manufacture. The final product-associated manuals, software and extra cables included with a laptop for sale were excluded from our study because their contribution to the total footprint is negligible. To analyse the process in greater detail, this study further broke down the manufacturing process into two phases: production and assembly.

\section{1) LCD production}

The LCD module includes the LCD panel, the backlight unit and the main LCD controller-printed wiring board. Manufacturing of an LCD requires many photolithographic processing steps to pattern the transistors, electrodes and colour filters onto glass substrates. Various photolithographic chemicals are used during production (Socolof and Overly, 2005). The LCD module has been shown to have the greatest contribution to the carbon footprint of LCD screen manufacturing, while the production of glass and its coatings is recognized as the most environmentally intense sub-process in the manufacture of LCD modules (Teehan et al., 2012; Arushanyan, 2014).

Compared to some developed countries, China has not yet reached an advanced level of manufacturing for such displays. As a result, China still relies on imports from developed countries, such as Germany, Japan, and the United States, for some of the raw materials and components used in this process. According to the available literature and the research conducted in this study, the major components of a laptop's display, including glass substrates and liquid crystals, are primarily imported; however, the assembly of these components occurs in China. Fluoride emissions account for most of the carbon footprint of the display production process. Fluorides are primarily generated during the etching process used to produce TFT glass. This process is performed in China. Fluorides mainly consist of $\mathrm{BF}_{3}, \mathrm{HF}$, and $\mathrm{NF}_{3}$ at a ratio of $1: 5: 25$. According to the environmental impact assessment report of a Chinese display manufacturer, $1.75 \mathrm{E}^{-6} \mathrm{~kg}, 8.6 \mathrm{E}^{-6} \mathrm{~kg}$, and $4.3 \mathrm{E}^{-5} \mathrm{~kg}$ of $\mathrm{BF}_{3}, \mathrm{HF}$ and $\mathrm{NF}_{3}$ emissions, respectively, are generated during the production of a $14^{\prime \prime}$ display.

\section{2) Motherboard production}

A motherboard is a general term used to identify the printed circuit board (PCB) and its embedded components or a bare printed wiring board with many slots, components, chipsets and heat sinks, included in the production of a laptop. Integrated circuit (IC) production is the biggest contributor of motherboard carbon emissions, followed by PCB production. The major raw materials and components of motherboard, such as heavy metals, are available in China, except ICs, which rely on imported materials.

\section{3) Casing production}

Most laptop casings are made of polycarbonate (PC) plastic and alloy. In this study, we assumed that a laptop casing consists of $60 \%$ PC plastic and $40 \%$ alloy. A laptop casing is created via plastic moulding and processing and alloy pressure casting. Because the techniques and materials used to produce various laptop casings are almost the same, we were able to collect casing data by simply weighing the casings of disposed laptops of the same size (Data source: actual weights, Table 2).

\section{4) Battery production}

China has become the primary supplier of lithium batteries for the global market; therefore, the batteries used in most export laptops typically originated in China. As a result, the parameters of the battery used in these calculations were based on China's battery data. The major raw materials of lithium battery include the anode material $\left(\mathrm{LiFePO}_{4}\right)$, a cathode graphite electrode, and an electrolyte, which is mainly composed of $\mathrm{LiPF}_{6}$ and diaphragm material.

\section{5) Transportation}

In this study, the transportation effect was calculated as the distance from the assembly factory to the selling location. Because the laptop is an export product, its transportation distance includes both domestic and overseas travel, including inland and maritime transportation. Domestic transportation was calculated from the assembly factory to the customs post, while overseas travel was calculated from customs to the final selling location. In China, the laptop-assembly industry is mainly located in the Yangtze River Delta, and Kunshan (in Suzhou) is the primary assembly location. Laptops are sent to the closest harbour, Shanghai, for export. Because the USA imports the largest number of laptops in the world, the USA was assumed to be the import country in this study. Thus, inland transportation was calculated from Suzhou to Shanghai, and maritime transportation was calculated from Shanghai to the USA.

Table 2

Materials for laptop casing production.

\begin{tabular}{lll}
\hline Material & Weight & Major technique \\
\hline Anti-pressure PC & $0.3262 \mathrm{~kg}$ & Plastic stretching and extrusion \\
Mg Alloy & $0.2178 \mathrm{~kg}$ & Mg alloy pressure casting \\
\hline
\end{tabular}




\section{Geographical distribution}

The production of laptop components detailed in this study occurred at sites based on the assumptions and scenarios described in Section 3.1.2. Subsequently, Simapro with RCEES LCI was used to model and analyse the inventory of parts produced both domestically and abroad. This analysis revealed that the carbon footprint generated by domestic production processes and their components was $120 \mathrm{~kg} \mathrm{CO} 2 \mathrm{eq}$ (Fig. 4). The production and assembly processes associated with the display screen were the largest contributors to carbon emissions, producing a total of $31.3 \mathrm{~kg} \mathrm{CO}$ eq or $26 \%$ of domestic export laptop carbon emissions. Thus, although the overall mass of the LCD component is relatively low, its impact is significant. The production of the outer case and the motherboard accounted for the second and third largest contributions to domestic emissions, equivalent to $26.3 \mathrm{~kg} \mathrm{CO}{ }_{2} \mathrm{eq} \mathrm{(22 \% )} \mathrm{and} 25 \mathrm{~kg}$ $\mathrm{CO}_{2}$ eq $(21 \%)$, respectively. These processes generate such high carbon emissions because $\mathrm{NF}_{3}, \mathrm{SF}_{6}$, and other acidic liquids are utilized when assembling the laptop display screen. Although package is relatively large components of a laptop's production by mass, its carbon footprint is negligible because most of its mass is made of carbon-neutral material, such as paper or cardboard. As seen in Fig. 4, the carbon footprint of a battery is relatively high because the raw materials, for upstream extraction and processing generate a large carbon footprint.

The overseas portion of production and its inherent components generate a carbon footprint of $69 \mathrm{~kg} \mathrm{CO}$ eq. The largest contributor to this value is the production of the ICs for the motherboard, which generates a total of $59.2 \mathrm{~kg} \mathrm{CO} 2 \mathrm{eq}$ or $86 \%$ of the total international carbon emissions associated with laptop production (Fig. 4). The negative effect of ICs is largely derived from their energy-intensive manufacturing processes, especially those processes used in silicon wafer manufacturing. In turn, wafer manufacturing accounts for most of the emissions generated during the production of PCBs. The second highest contributor is LCD screen production, primarily because of the emissions generated by its most crucial raw material, liquid crystals, which are produced abroad. The production of liquid crystals releases large quantities of nitrogen oxide and acid gas into the atmosphere.

The characteristics of the carbon transfer occurring in China with respect to export laptops can be further summarized as follows: $33.3 \%$ of carbon emissions from the export laptop-production process originate from components primarily produced abroad, and $66.7 \%$ of carbon emissions stem from components primarily produced domestically. The carbon footprint of export laptops is the result of both domestic and international processes, while the demand from foreign markets is the dominant factor driving carbon emissions from laptop production in China.

\section{Discussion}

This study selected the most popular 14-inch laptop model (by export volume) and adopted a bottom-up method to analyse the carbon footprint of this product's entire life cycle. The domestic and foreign allocation of carbon emissions generated by the production and transportation of this typical Chinese product allows for a better understanding of both the structure of a carbon footprint and its impact. The geographical analysis of the data and the production chain, as well as the on-site application of data, was emphasized. Based on relevant industry development reports, we performed a geographical allocation of the carbon footprint of laptop parts and identified the impacts of their import and export to the greatest extent possible. We used "one unit", or a typical export laptop, as the measurement criterion to conduct our in-depth analysis. Because it is impossible to accurately illustrate the application of each laptop and the use of laptop components in traded products (for instance, although an imported hard drive may be used in exported computers, it may also be sold and used in computers domestically), we were unable to infer overall macro carbon transfer levels from this single case. However, this study does provide a general understanding of the geographical distribution of a typical processing trade product's carbon footprint during its major life cycle stages.

Usage and end-of-life processes were not considered in this paper. One reason for this is that many case studies have explored the lifespan of a laptop, and these studies indicate that the manufacturing phase is responsible for nearly half of the total carbon footprint of the product (Eugster et al., 2007; O'Connell and Stutz, 2010; Yao et al., 2010). Another reason is that, given the importance and complexity of the end-of-life footprint of a laptop, this topic would be more appropriately considered in a separate study. Because most used laptops from developed countries return to China for disassembly and reuse via illegal imports, we are currently unable to obtain official or authoritative reports on laptop waste to calculate its carbon footprint.

Process-sum LCA methods have been used in many studies of ICT equipment, and some data are available from commercial databases, such as Gabi and EcoInvent (Teehan and Kandlikar, 2013).

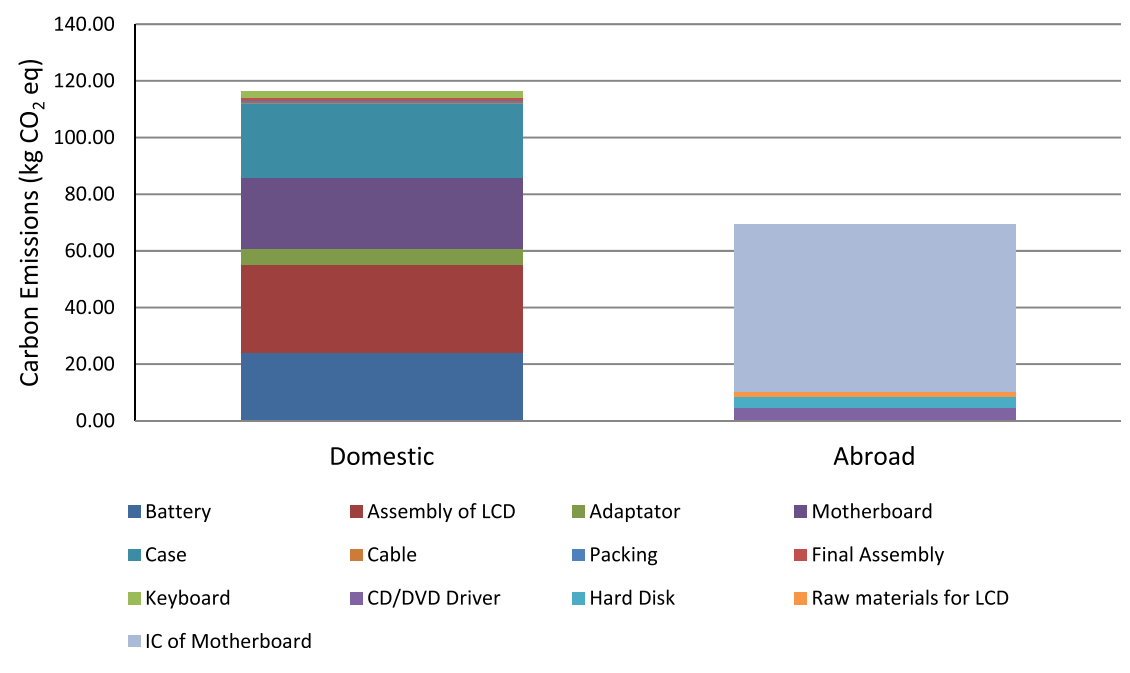

Fig. 4. Carbon footprint from the domestic and international components used in laptop production. 
When compared with other studies, our results indicate relatively high emissions. This is because China has a coal-dominated electricity system. The $\mathrm{CO}_{2}$ intensity of the electricity sector is significantly higher than that in other countries, with approximately 51.7\% of all embodied emissions in MEM coming from electricity generation (Lin and Sun, 2010). Thus, because other study results range from 93 to $360 \mathrm{~kg} \mathrm{CO}$ eq (Choi et al., 2006; Teehan et al., 2013; Song et al., 2013), our research results are credible.

Nevertheless, many uncertainties exist in our approach and data. The estimation of the emissions embodied in a product requires some methodological assumptions and is dependent on the quality of the data used. Although this approach creates uncertainties, a detailed breakdown of the production process and its geographical distribution illustrates that the carbon quota for exports is often overestimated in current research. This is because the importance of geographical distribution in carbon footprint analyses is often not completely understood. However, even with these limitations, our study shows that by breaking down the production chain in detail, the most critical hotspots relating to the production of carbon emissions can be identified, thereby providing support for more targeted trade policies.

\section{Conclusions and policy implications}

China is unique globally because it accounts for $80 \%$ of the increase in global $\mathrm{CO}_{2}$ emissions since 2008 (Peters et al., 2011, 2012). The surge in China's exports has been partially blamed for this increase in emissions (Michieka et al., 2013). Facing both international pressure to curb its $\mathrm{CO}_{2}$ releases and domestic complaints about great air pollution, China must reduce its $\mathrm{CO}_{2}$ emissions embodied in exports (Xu et al., 2010; Liu, 2013) and implement related policies, as has been widely discussed (Pan et al., 2008; Wang et al., 2008). The Chinese government frequently adjusts its foreign trade policy (for example, by imposing export restrictions on energy-intensive industries), and the development of a lowcarbon economy has been established as a target for guiding the rational development of export industries (Cui et al., 2015).

This paper reports a process-based $\mathrm{CO}_{2}$ emission pattern case study of an export product. The bottom-up approach used here is a more feasible and informative method for trade policy makers than the top-down approach used elsewhere. This process differs from that used in developing long-term policies, including industrial transformation, cooperative trade agreements, technology transfer, and carbon tariffs, in that it supports process-based technological improvements and other near-term policies. One of the largest mechanical and electrical product exports, the laptop, is also a high-carbon intensity product according to the results found here. The assembly of the LCD module is one of the most carbonintensive processes in a laptop's construction, and as a result, the transfer of the LCD assembly process may be a direct means to reduce the carbon emissions from laptops that could eliminate the need to decrease laptop exports. Reducing or transferring the process with the highest carbon emissions instead of reducing the size of the laptop industry as a whole would be a win-win strategy in terms of both promoting economic development and reducing carbon emissions in China.

This process-based $\mathrm{CO}_{2}$ emissions pattern case study can also contribute to reducing carbon emissions from a product life cycle perspective. The transfer or reduction of carbon-intensive processes in one country will not necessarily create a more sustainable product, especially if the carbon-intensive process (e.g., the assembly of an LCD module) is transferred to a less-developed country. In fact, the expansion of carbon-intensive industries in other countries may reduce China's efforts toward global energy savings and global warming alleviation. Therefore, it is necessary to identify the distribution of a product's carbon footprint among different countries and different life cycle stages, as shown in this study. Such an initiative should be used to improve the energy efficiency of the original production processes rather than simply shifting the processes to less-developed countries, to achieve both GHG emissions reduction and sustainable development targets.

\section{Acknowledgements}

We acknowledge the support of the National Natural Science Foundation of China (Grant Nos. 71303231) and the support of the Strategic Priority Research Program of the Chinese Academy of Sciences (no. XDA05140200, XDA05140105).

\section{References}

Arushanyan, Y., Ekener-Petersen, E., Finnveden, G., 2014. Lessons learned - review of LCAs for ICT products and services. Comput. Ind. 65 (2), 211-234.

Atkinson, G., Hamilton, K., Ruta, G., Mensbrugghe, D., 2011. Trade in 'virtual carbon': empirical results and implications for policy. Glob. Environ. Change 21 (2), $563-574$.

Caney, S., 2009. Justice and the distribution of greenhouse gas emissions. J. Glob. Ethics 5 (2), 125-146.

Choi, B.-C., Shin, H.-S., Lee, S.-Y., H, T., 2006. Life cycle assessment of a personal computer and its effective recycling rate. Int. J. Life Cycle Assess. 11 (2), 122-128.

Cui, L.B., Peng, P., Zhu, L., 2015. Embodied energy, export policy adjustment and China's sustainable development: a multi-regional input-output analysis. Energy 82, 457-467.

Davis, S.J., Caldeira, K., 2010. Consumption-based accounting of $\mathrm{CO}_{2}$ emissions. Proc. Natl. Acad. Sci. U. S. A. 107 (12), 5687-5692.

Eugster, M., Hischier, R., Duan, H.B., 2007. Key Environmental Impacts of the Chinese EEE-Industry: A Life Cycle Assessment Study. EMPA: Materials Science \& Technology, Switzerland. http://library.eawag-empa.ch/empa_publications_ 2007_open_access/EMPASG20070177.pdf.

Feng, K.S., Sun, L.X., Guan, D.B., Liu, W.D., Liu, Z., Hubacek, K., 2013. Outsourcing $\mathrm{CO}_{2}$ within China. Proc. Natl. Acad. Sci. U. S. A. 110 (28), 11654-11659.

General Administration of Customs of the People's Republic of China, 2013. Customs Statistic Yearbook 2013. Beijing.

Gregg, J.S., Andres, R.J., Marland, G., 2008. China: emissions pattern of the world leader in $\mathrm{CO}_{2}$ emissions from fossil fuel consumption and cement production. Geophys. Res. Lett. 35 (8), L08806.

Kim, S., Hwang, T., Overcash, M., 2001. Life cycle assessment study of color computer monitor. Int. J. Life Cycle Assess. 6 (1), 35-43.

Lee, K.-H., 2011. Integrating carbon footprint into supply chain management: the case of Hyundai Motor Company (HMC) in the automobile industry. J. Clean. Prod. 19 (11), 1216-1223.

Lin, B., Sun, C., 2010. Evaluating carbon dioxide emissions in international trade of China. Energy Policy 38 (1), 613-621.

Lindner, S., Legault, J., Guan, D., 2012. Disaggregating input-output models with incomplete information. Econ. Syst. Res. 24 (4), 329-347.

Liu, R.L., 2011. The present situation and tendency of notebook computer industrial development. Sci. Technol. Dev. 5, 86-91.

Liu, Z., 2013. A low-carbon road map for China. Nature 500, 143-145.

Liu, W.D., Lu, D., 2010. A Sketch Map of Low-carbon Economic Development in China. The Commercial Press, Beijing.

Michieka, N.M., Fletcher, J., Michieka, W.B., 2013. An empirical analysis of the role of China's exports on $\mathrm{CO}_{2}$ emissions. Appl. Energy 104, 258-267.

O'Connell, S., Stutz, M., 2010. Product carbon footprint (PCF) assessment of Dell laptop - results and recommendations. In: Sustainable Systems and Technology (ISSST), 2010 IEEE International Symposium on May 2010.

Pan, J., Phillips, J., Chen, Y., 2008. China's balance of emissions embodied in trade: approaches to measurement and allocating international responsibility. Oxf. Rev. Econ. Policy 24 (2), 354-376.

Peters, G.P., Hertwich, E.G., 2006. Pollution embodied in trade: the Norwegian case. Glob. Environ. Change 16 (4), 379-387.

Peters, G.P., Hertwich, E.G., 2008. $\mathrm{CO}_{2}$ embodied in international trade with implications for global climate policy. Environ. Sci. Technol. 42 (5), 1401-1407.

Peters, G.P., Minx, J.C., Webe, C.L., 2011. Growth in emission transfers via international trade from 1990 to 2008. Proc. Natl. Acad. Sci. U. S. A. 108 (21), 8903-8908.

Peters, G.P., Marland, G., Quéré, C.L., Boden, T., Canadell, J.G., Raupach, M.R., 2012. Rapid growth in $\mathrm{CO}_{2}$ emissions after the 2008-2009 global financial crisis. Nat. Clim. Change 2 (1), 2-4.

Shui, B., Harriss, R.C., 2006. The role of $\mathrm{CO}_{2}$ embodiment in US-China trade. Energy Policy 34 (18), 4063-4068. 
Skelton, A., Guan, D., Peters, G.P., Crawford-Brown, D., 2011. Mapping flows of embodied emissions in the global production system. Environ. Sci. Technol. 45 (24), 10516-10523.

Socolof, M.L., Overly, J.G., Geibig, J.R., 2005. Environmental life-cycle impacts of CRT and LCD desktop computer displays. J. Clean. Prod. 13, 1281-1294.

Song, Q.B., Wang, Z.S., Li, J.H., Yuan, W.Y., 2013. Life cycle assessment of desktop PCs in Macau. Int. J. LCA 18, 553-566.

Su, B., Ang, B.W., 2011. Multi-region input-output analysis of $\mathrm{CO}_{2}$ emissions embodied in trade: the feedback effects. Ecol. Econ. 71, 42-53.

Sun, X., Liu, J.R., Yang, D., Lu, B., 2014. The carbon footprint of household airconditioners and its key influence factors. ACTA Sci. Circumst. 34 (4), 1054-1060.

Teehan, P., Kandikar, M., 2012. Sources of variation in life cycle assessments of desktop computers. J. Ind. Ecol. 16 (S1), 182-194.

Teehan, P., Kandlikar, M., 2013. Comparing embodied greenhouse gas emissions of modern computing and electronics products. Environ. Sci. Technol. 47, 3997-4003.

Wang, T., Watson, J., 2008. China's carbon emissions and international trade: implications for post-2012 policy. Clim. Policy 8 (6), 577-587.
Weber, C.L., Peters, G.P., 2009. Climate change policy and international trade: policy considerations in the US. Energy Policy 37 (2), 432-440.

Weber, C.L., Peters, G.P., Guan, D.B., Hubacek, K., 2008. The contribution of Chinese exports to climate change. Energy Policy 36 (9), 3572-3577.

Wiedmann, T., Minx, J., 2008. A definition of 'carbon footprint'. In: Pertsova, C.C. (Ed.), Ecological Economics Research Trends: Chapter 1. Nova Science Publishers, Hauppauge NY, USA, pp. 1-11.

Xu, M., Williams, E., Allenby, B., 2010. Assessing environmental impacts embodied in manufacturing and labor input for the China-U.S. trade. Environ. Sci. Technol. 44 (2), 567-573.

Xu, M., Li, R., Crittenden, J.C., Chen, Y.S., 2011. $\mathrm{CO}_{2}$ emissions embodied in China's exports from 2002-2008: a structural decomposition analysis. Energy Policy 39 (1), 7381-7388.

Yang, D., Liu, J.R., Yang, J.X., Ding, N., 2015. Life-cycle assessment of China's multicrystalline silicon photovoltaic modules considering international trade. J. Clean. Prod. 94, 35-45.

Yao, M.A., Higgs, T.G., Cullen, M.J., Stewart, S., 2010. Comparative assessment of life cycle assessment methods used for personal computers. Environ. Sci. Technol. 44 (19), 7335-7346. 